Vol. 2 | No. 2 | $2021 \mid$ Hal. 101-105

\title{
MENINGKATKAN PEREKONOMIAN MASYARAKAT DI MASA PANDEMI COVID-19 PADA USAHA MIKRO, KECIL DAN MENENGAH (UMKM) MELALUI PEMANFAATAN MEDIA ONLINE
}

\author{
Imam Safi'i*, Muhammad Daffa Aulia, Muhammad Haidir Ali, Farih Tsabitah Imtinan, \\ Santia Fitrotun Nisak, Anggita Wilda Pangestu, Lailatul Mufidayatus Sholikah, \\ Yunara Maufiroh \\ Fakultas Agama Islam, Universitas Islam Malang \\ *korespondensi email: imam.safii@unisma.ac.id
}

\begin{abstract}
ABSTRAK
Tujuan yang ingin dicapai adalah meningkatkan perekonomian masyarakat di masa pandemic Covid-19 pada Usaha Mikro, Kecil dan Menengah (UMKM) melalui pemanfaatan media online pada warga Dusun Krajan, Desa Ngabab, Kecamatan Pujon, Kabupaten Malang. Perekonomian warga tersebut menurun akibat adanya pandemic covid-19. Oleh karena itu perlu dilakukan upaya untuk mengatasi permasalahn tersebut. Metode yang digunakan dalam kegiatan ini adalah metode partisipatif. Metode partisipatif adalah metode pendampingan yang bertujuan untuk memberdayakan kelompok masyarakat atau kelompok mitra dalam menyelesaikan permasalahannya. Pihak yang terkait dalam kegitan ini adalah masyarakat Dusun Krajan, Desa Ngabab, Kecamatan Pujon, Kabupaten Malang. Bentuk kegiatan yang dilakukan diantaranya adalah melakukan survey, melakukan penyuluhan, melakukan praktik dan evaluasi. Kegiatan yang dilaksanakan yaitu memasarkan produk UMKM Yogurt Dworowati melalui media online yaitu WhatsApp. Hasil dari kegiatan ini adalah pemilik UMKM Yogurt Dworowati memperoleh penghasilan yang lebih banyak dari biasanya yang dapat digunakan untuk menunjang kembali perekonomiannya.
\end{abstract}

Kata Kunci: perekonomian; UMKM; media online

\section{PENDAHULUAN}

Dari segi ekonomi, pandemi Covid-19 telah menimbulkan berbagai dampak. Begitu pula dari segi kesehatan, pendidikan, perubahan pola aktivitas, dll. Dalam sebuah penelitian, dikatakan tentang kemungkinan terjadinya pandemi Covid-19 yang membawa resiko besar bagi perekonomian dunia termasuk Indonesia baik dari segi pariwisata, perdagangan dan investasi (Purwanto, 2021). Pandemi Covid-19 memberikan dampak signifikan, banyak masyarakat yang mengeluh karena aktivitasnya terhenti akibat adanya pandemic ini (Livana et al., 2020; Masruroh \& Hayati, 2021). Banyak masyarakat yang kesulitan untuk memenuhi kebutuhannya sehari-hari dikarenakan adanya Pemutusan Hubungan Kerja (PHK) bagi masyarakat yang bekerja di sebuah perusahaan (Yanuarita \& Haryati, 2020). Permasalahan tersebut dialami oleh wargamasyarakat Dusun Krajan, Desa Ngabab, Kecamatan Ngantang, Kabupaten Malang. Sehingga perlu adanya upaya yang dilakukan agar perekonomian masyarakat dusun tersebut tidak semakin menurun.

Di Indonesia, UMKM merupakan salah satu bidang usaha yang memiliki peranan penting bagi pertumbuhan ekonomi, selain itu UMKM juga turut andil dalam penyerapan 
tenaga kerja dan distribusi hasil usahanya. Dalam sepuluh tahun terakhir, pertumbuhan jumlah unit UMKM tahun 2016-2019 mengalami peningkatan sebesar 4,2 persen setiap tahunnya dan rata-rata kontribusi UMKM tehadap Produk Domestik Bruto (PDB) Indonesia selama 3 tahun terakhir lebih dari 50 persen. Hal ini membuktikan bahwa UMKM mampu mendongkrak sekotor perekonomian secara mandiri dan mendukung lzju pertumbuhan ekonomi di Indonesia (Desiani et al., 2021; Nurlinda \& Sinuraya, 2020; Soetjipto, 2020).

Pada Bulan Juli 2020, Indonesia mulai menerapkan kebijakan tatanan hidup baru atau biasa disebut dengan Era New Normal. Menurut Kariem, Era New Normal merupakan era ketidakpastian baik dalam kondisi ekonoi, social dan kesehatan. Pada masa ini telah memunculkan perubahan aktivitas yang berhubungan dengan media online saat menjalankan kebiasaannya, seperti membangun kegiatan ekonomi seperti Usaha Mikro, Kecil, dan Menengah (UMKM) dengan memanfaatkan media online. Noer Sortjipto dalam bukunya yang berjudul Ketahanan UMKM Jawa Timur Melintasi Pandemi Covid-19 mengemukakan bahwa UMKM adalah kelompok usaha yang memiliki jumlah paling besar dan kelompok ini terbukti tahan terhadap berbagai macam goncangan krisis ekonomi.

Pada tanggal 3 Februari 2021 mahasiswa dari Kelompok 17 KSM-Tematik Edisi Covid-19 Universitas Islam Malang, melaksanakan kegiatan pemberdayaan masyarakat untuk menyalurkan ilmu demi mewujudkan masyarakat yang berkembang dan kreatif. Pemberdayaan masyarakat merupakan suatu proses yang bertujuan untuk melakukan beberapa kegiatan berbasis bergotongroyong dalam masyarakat tersebut untuk adanya suatu perubahan. Pemberdayaan masyarakat merupakan suatu upaya untuk memberikan kemampuan sekaligus kesempatan kepada masyarakat untuk ikut berperan aktif dalam pembangunan desa (Umanailo, 2019). Oleh karena itu kegiatan tersebut diharapkan mampu untuk menyelesaikan permasalahan yang sedang terjadi di lingkungan masyarakat. Berdasarkan uraian yang telah dipaparkan, permasalahan yang terjadi adalah menurunnya kondisi perekonomian masyarakat akibat dampak dari adanya pandemiccovid-19. Program pelaksanaan kegiatan KSM-Tematik Edisi Covid-19 Kelompok 17 iniadalah meningkatkan perekonomian masyarakat di masa pandemic covid-19 pada Usaha Mikro, Kecil, dan Menengah (UMKM) melalui pemanfaatan media online.

\section{METODE}

Metode yang digunakan dalam kegiatan ini adalah metode partisipatif. Metode partisipatif adalah metode pendampingan yang bertujuan untuk memberdayakan kelompok masyarakat atau kelompok mitra dalam menyelesaikan permasalahannya (Ilsan, Salim, \& Husain, 2020). Pihak yang terkait dalam kegitan ini adalah masyarakat Dusun Krajan, Desa Ngabab, Kecamatan Pujon, Kabupaten Malang. Bentuk kegiatan yang dilakukan diantaranya adalah melakukan survey, melakukan penyuluhan, melakukan praktik dan evaluasi.

Berdasarkan bentuk kegiatan di atas, terdapat rincian kegiatan diantaranya tahap pertama yaitu melakukan survey ke Desa Ngabab terkait dengan informasi penduduk di desa tersebut, tahap kedua yaitu melaksanakan penyuluhan ke masyarakat mengenai progam Kelompok 17 KSM-Tematik Edisi Covid-19 Universitas Islam Malang yang akan dijalankan yaitu meningkatkan perekonomian masyarakat di masa pandemi Covid-19 pada Usaha Mikro, Kecil dan Menengah (UMKM) melalui pemanfaatan media online, tahap ketiga yaitu melakukan praktik kegiatan tersebut pada salah satu UMKM YoghurtDworowati milik Ibu Tatik warga Dusun Krajan, Desa Ngabab, Kecamatan Pujon, Kabupaten Malang. Bentuk penerapan tersebut yaitu memasarkan produk yogurt melalui media online. Serta tahap terakhir yaitu melakukan evaluasi mengenai tingkat keberhasilandari usaha tersebut. 


\section{HASIL DAN PEMBAHASAN}

Majunya UMKM di Inonesia tidak terlepas dari perkembangan teknologi yang terjadi saat ini. Beberapa penelitian menunjukkan salah satu factor yang mendukung perkembangan UMKM adalah karena pemanfaatan sarana TIK (Teknologi Informasi dan Komunikasi). Para pelaku usaha mulai memanfaatkan sarana teknologi seperti smartphone untuk memasarkan produknya, serta menggunakan aplikasi komunikasi seperti WhatsApp dan media social untuk melebarkan pasar usahanya.

Usaha untuk meningkatkan perekonomian pada Usaha Mikro, Kecil dan Menengah (UMKM) di masa pandemi Covid-19 melalui media online ini berupaya untuk mengatasi masalah penurunan ekonomi yang dialami oleh warga Dusun Krajan, Desa Ngabab, Kecamatan Pujon, Kabupaten Malang. Pada tahap ini, pelaksana kegiatan yaitu Kelompok 17 KSM-Tematik Edisi Covid-19 Universitas Islam Malang mencari informasi dengan Bapak Amin Affandi selaku Kepala Desa Ngabab, hal ini dilakukan untuk memperoleh informasi tentang data-data beserta kondisi penduduk pada masa pandemic Covid-19 ini. Dari hasil survey dan wawancara bersama Kepala Desa tersebut telah ditemukan bahwa kondisi perekonomian penduduk di Desa Ngabab saat ini masih bisa dikatakan normal, tetapi juga banyak penduduk yang mengalami penurunan penghasilan akibat adanya pandemic Covid19 ini.

Tahap kedua yaitu melakukan penyuluhan ke masyarakat. Pada tahap ini pelaksana kegiatan melakukan edukasi mengenai alternative pemasaran yang terhambat disaat pandemi, yaitu dengan menggunakan media online. Hal ini dilakukan agar masyarakat memahami bahwa kegiatan tersebut merupakan salah satu solusi yang tepat untuk meningkatkan kembali penurunan ekonomi akibat pandemic ini, dan pemanfaatan media online memberikan banyak manfaat bagi dunia bisnis ke depannya. Dengan melakukan ini juga dapat memperluas mangsa pasar, sehingga tidak hanya bergantung pada penghasilan dengan membuka lapak atau toko di depan rumah saja. Mangsa pasar dari bisnis online akan jauh lebih luas karena semua orang di Indonesia bahkan di dunia dapat mengakses internet sehingga produk yang ditawarkan via internet akan jauh lebih mudah dan lebih laris.

Tahap ketiga yaitu melakukan praktik dengan memanfaatkan media online bersama pemilik UMKM Yogurt Dworowati yang dipasarkan melalui media online. Di zaman sekarang, masyarakat sering menggunakan aplikasi WhatsApp sebagai komunikasi jarak jauh antara satu sama lain secara efektif dalam melakukan transaksi jual beli. WhatsApp memiliki kelebihan untuk berkirim pesan teks tanpa batas, audio, voice call, video call, mengirim gambar, foto maupun mengirim audio tanpa ada batasnya (Harahap \& Kurniawati, 2018). Rincian kegiatan yang dilakukan dalam tahap ini yang pertama yaitu memproduksi olahan yogurt dworowati dengan berbagai macam rasa. Bahan baku utama untuk produksi yogurt ini yaitu susu sapi murni segar yang diolah dengan higenis dan terjamin. Olahan yogurt ini terdiri dari berbagai bentuk berupa yogurt lilin, yogurt botol, susu segar, susu pasteurisasi dan aneka olahan susu lainnya. Yogurt lilin yang merupakan produk unggulan dari UMKM ini dijual seharga Rp. 14.000 dengan satu pack berisi 20 biji. Menurut penuturan Ibu Tatik, Yogurt Dworowati telah berdiri sejak tahun 2013 dan pengiriman yogurt bukan hanya di wilayah Pujon saja, melainkan telah sampai ke Luar Jawa Timur. Sebelum adanya pandemic, produksi yogurt bisa mencapai 80 liter. Namun, adanya pandemic mengakibatkan penurunan pada produksi yogurt, menjadi hanya 30liter saja. Selanjutnya yaitu pelaksana kegiatan yang terdiri dari Kelompok 17 KSM-Tematik Edisi Covid-19 Universitas Islam Malang membuat brosur penjualan yang akan diposting diaplikasi WhatsApp yaitu story (status) agar produk bisa dikenal oleh banyak kalanganmasyarakat. 


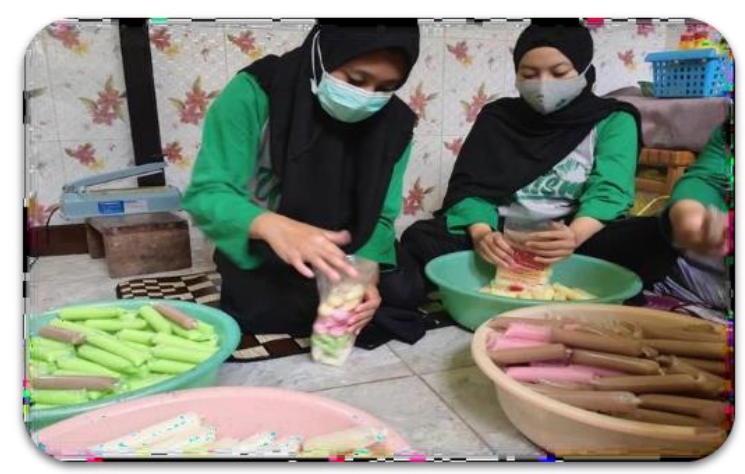

Gambar 1. Proses produksi Yogurt Dworowati

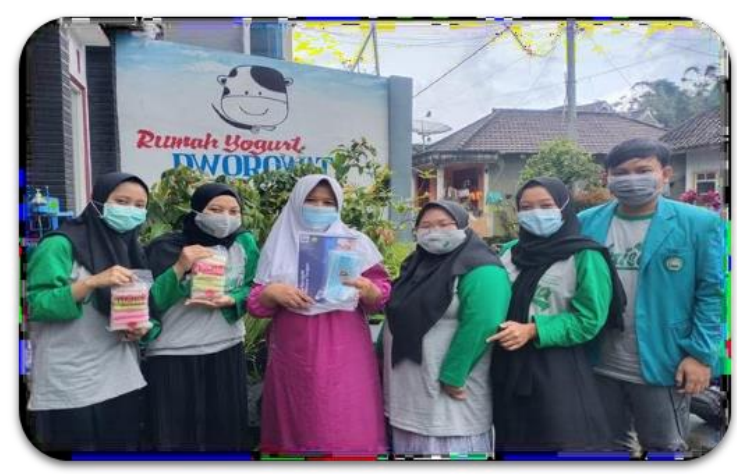

Gambar 2. Produk Jadi Yogurt Dworowati

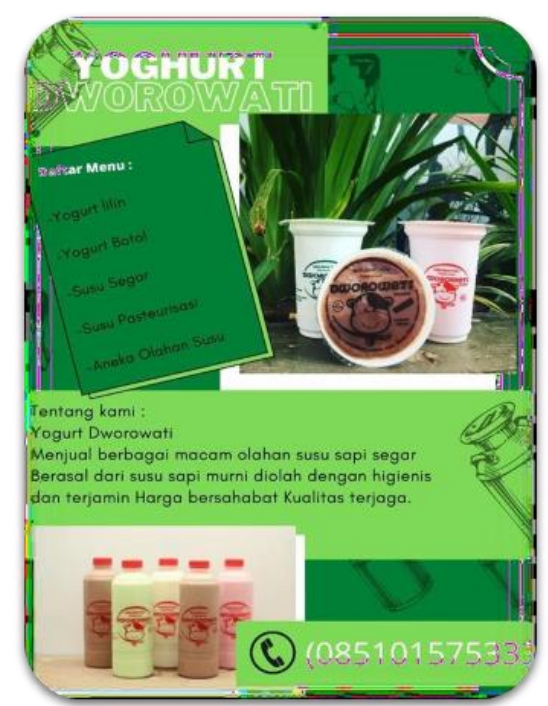

Gambar 3. Brosur Produk Yogurt Dworowati

Pada tahap terakhir, dilakukan kegiatan evaluasi. Dalam tahap ini pelaksana kegiatan melihat bagaimana hasil untuk UMKM dengan memanfaatkan media online yang telah dijalankan. Hasil ini ditunjukkan dengan diperolehnya penghasilan pada tanggal 26 Februari 2021 sekitar Rp. 450.000. Melalui kegiatan ini pula, masyarakat Desa Ngabab menjadi mengerti tentang manfaat adanya media online dalam aktivitas bisnis. Berdasarkan hal tersebut, diharapkan kegiatan ini dapat selalu diterapkan agar dapat mempermudah aktivitas bisnis serta dapat membantu dalam masalah perekonomian masyarakat khususnya masyarakat Dusun Krajan, Desa Ngabab, Kecamatan Pujon, Kabupaten Malang. 


\section{KESIMPULAN}

Berdasarkan hasil kegiatan Kelompok 17 KSM-Tematik Edisi Covid-19 Universitas Islam Malang dapat disimpulkan bahwa, permasalahan penurunan ekonomi masyarakat Dusun Krajan, Desa Ngabab, Kecamatan Pujon, Kabupaten Malang yang terjadi akibat adanya pandemic covid-19 dapat diatasi. Solusi yang dapat digunakan yaitu dengan memasarkan produk UMKM Yogurt Dworowati melalui media online. Masyarakat yang mengalami penurunan khususnya pemilik UMKM Yogurt Dworowati dapat menerapkan solusi tersebut, sehingga memperoleh penghasilan yang bisa digunakan untuk menunjang kembali kebutuhan perekonomian.

Media online sangat mendukung dalam meningkatkan perekonomian pada UMKM (Usaha Mikro, Kecil, dan Menengah) yang memberikan dampak positif dalam dunia bisnis seperti saat menjalankan usaha yogurt ini. Salah satu media online yang digunakan dalam kegiatan ini yaitu WhatsApp. Aplikasi tersebut digunakan sebagai alat komunikasi yang efektif dan efisien. Adanya UMKM Yogurt Dworowati ini dengan memanfaatkan media online yang telah dijalankan diharapkan mampu menciptakan perekonomian yang baik di masa mendatang.

\section{DAFTAR RUJUKAN}

Desiani, A., Putri, A. I., Yuniar, E., Calista, A., Makhalli, S., \& Amran, A. (2021). Pemanfaatan marketplace shopee sebagai meningkatkan pemasaran kain songket. Jurnal Inovasi Hasil Pengabdian Masyarakat (JIPEMAS), 4(2), 209-219. https://doi.org/10.33474/jipemas.v4i2.9222

Livana, Suwoso, R. H., Febrianto, T., Kushindarto, D., \& Aziz, F. (2020). Dampak Pandemi Covid-19 bagi Perekonomian Masyarakat Desa. Indonesian Journal of Nursing and Health Sciences, 1(1), 37-48. https://doi.org/https://orcid.org/0000-0002-49057214

Masruroh, \& Hayati, N. (2021). Media poster sebagai sarana edukasi masyarakat dalam upaya pencegahan covid-19. Jurnal Inovasi Hasil Pengabdian Masyarakat (JIPEMAS), 4(36), 169-176. https://doi.org/10.33474/jipemas.v4i2.9207

Nurlinda, \& Sinuraya, J. (2020). Potensi UMKM Dalam Menyangga Perekonomian Kerakyatan di Masa Pandemi Covid-19 : Sebuah Kajian Literatur. Seminar Akademik Tahunan Ilmu Ekonomi Dan Studi Pembangunan, 160-175.

Purwanto, A. (2021). Ekonomi Dunia di Massa Pandemi Covid-19: Dari Dampak Hingga Proyeksi Pertumbuhan 2021-2022. Kompaspedia. https://kompaspedia.kompas.id/baca/paparan-topik/ekonomi-dunia-di-masapandemi-covid-19-dari-dampak-hingga-proyeksi-pertumbuhan-2021-2022

Soetjipto, N. (2020). Ketahanan UMKM Jawa Timur Melintasi Pandemi Covid-19. K-Media.

Yanuarita, H. A., \& Haryati, S. (2020). Pengaruh Covid-19 Terhadap Kondisi Sosial Budaya di Kota Malang dan Konsep Strategis Dalam Penanganannya. Jurnal Ilmiah Widya Sosiopolitika, 2(2), 58-71. https://doi.org/10.24843/JIWSP.2020.v02.i02.p01 